\title{
Anthropomorphism of AI-based Intelligent Customer Service, and Its Affective and Behavioral Consequences
}

\author{
Yu-Ting Chang-Chien \\ Department of Information Management \\ National Sun Yat-Sen University, Kaohsiung, Taiwan \\ s6450056@gmail.com \\ Jack Shih-Chieh Hsu \\ Department of Information Management \\ National Sun Yat-Sen University, Kaohsiung, Taiwan \\ jackshsu@mis.nsysu.edu.tw
}

\begin{abstract}
Recently, as many users turn to social media to interact with service providers, organizations apply Artificial intelligence (AI) to improve the efficiency and effectiveness of the operation. This type of customer service system is called intelligent customer service (ICS) which one of the most commonly adopted tools is chatbot. Since chatbot is AI-empowered, whether this system can effectively interact with customers and solve their problems is critical. However, the quality of ICS has received significant attention recently, and a lack of systematic study on the outcomes of anthropomorphism leaves this question unanswered in an ICS context. Based on a cognitive-affective-behavioral framework, this study attempts to understand whether anthropomorphism can promote desired behaviors (including usage and citizenship behaviors) through enhancing affective outcomes, such as satisfaction and identity. Data collected from 183 chatbotICS users, this study illustrates how anthropomorphism can increase quality, enhance satisfaction and identity. Furthermore, we also show that satisfaction and identity lead to further usage and citizenship behaviors. This highlights the importance of increasing anthropomorphism for the chatbot-ICS.
\end{abstract}

\section{Introduction}

Customer service is an organizational process that provides time, place and form utilities for customers during the pre-sale, sale and post-sale transactions [15]. Customer service is the moment of truth to impress, satisfy and retain customers. It is the way to build loyalty, improve customer satisfaction, and create market share [37]. The quality of customer service has been emphasized since last century [42]. Organizations invest a significant amount of money in customer service since it makes the company more competitive.

\author{
Jacob Chun Cheng \\ Department of Information Management \\ National Sun Yat-Sen University, Kaohsiung, Taiwan \\ jacobchun520@gmail.com \\ Yi wen Yeh \\ Department of Information Management \\ National Sun Yat-Sen University, Kaohsiung, Taiwan \\ dora161923@gmail.com
}

Recently, organizations apply Artificial intelligence (AI) in many areas to improve efficiency and effectiveness of operation. This type of customer service system is called intelligent customer service (ICS). For example, in the financial industry, customers interact with ICS to quest for financial information (e.g., bank statements) or solve personal financial problems (e.g., to cancel the lost credit card). In the telecom industry, customers quest for the amount and deadline for their bills. Since online education is getting popular because of Covid-19, ICS has been adopted to answer commonly asked questions. Many users turn to social media to interact with service providers, so many organizations implement ICS on social media. One of the most commonly adopted tools is chatbot, a conversational agent, defined as "a software system which exploits natural language technologies to engage users in information-seeking and task-oriented dialogue" [28].

With natural language processing (NLP) and deep learning techniques, chatbot can interact with customers with daily used language. Since chatbot is AI-empowered, it is critical to determine whether this system can effectively interact with customers and solve their problems. Recently, the quality of chatbot-ICS has received significant attention (e.g., Wen [63]). However, in addition to the ability of chatbot to interact with customers, whether it can smoothly interact with customers is also worth studying. Past studies have pointed out that AI-empowered systems can reach a better outcome if the system contains human-like features [65]. Anthropomorphism, how well the AI looks and interacts like a human being, has been highlighted in past studies [55]. Since chatbot are also AI-empowered, whether the anthropomorphism of chatbot leads to better interaction outcomes is therefore interesting. Past studies mainly focused on the direct outcome of anthropomorphism, such as social presence and intimacy 
$[1,48]$. It is reasonable to believe that anthropomorphism may generate other outcomes. However, a lack of systematic study on the outcomes of anthropomorphism leaves this question unanswered. Therefore, the first question of this study is "what are the outcomes of anthropomorphism in a chatbot-ICS context?"

AI-empowered customer service requires significant investment. How to increase the usage rate is the core concern of service providers. Expectancy theories point out that continued usage is a function of satisfaction [7, 34]. In addition to existing users, there is a need to extend the usage to new customers. This implies that effective promotion is critical for its success. Past studies have shown that citizenship behaviors conducted by loyal customers are critical for the spreading of word-of-mouth online [27]. Citizenship is voluntary and discretionary behavior conducted by customers. Those behaviors are not required for the successful production and/or delivery of the service but that, in the aggregate, benefit the service organization [27]. For example, helping other customers, providing feedback, and recommendations have commonly cited customer citizenship behaviors. Citizenship behaviors are more likely to be conducted by loyal customers, which are satisfied[29]. Therefore, lifting the level of satisfaction is critical to forming loyal customers, who tend to continue the service and conduct word-of-mouth. The way to improve customer satisfaction on chatbot-ICS is therefore important for promoting further usage. Another research question of this study is to understand "how to promote usage and citizenship behaviors?"

The purpose of this study is to understand the effect of anthropomorphism in a chatbot-ICS context. In addition, based on a cognitive-affective-behavioral framework, we also attempt to understand whether anthropomorphism (one type of cognition) can promote desired behaviors (including usage and citizenship behaviors) through enhancing affective outcomes, such as satisfaction and identity. In the following, we first introduce related concepts and build according to hypotheses. We then introduce the research method used for collecting required data and the analysis results based on the collected data. In the final section, implications and conclusions are provided.

\section{Literature review and hypotheses de- velopment}

\subsection{Chatbot-ICS}

Intelligent customer service (ICS) refers to the customer service with AI in types of text, voice, and robot. ICS has been adopted in many channels and offered personalized answers 24 hours every day to customers. Moreover, it can answer more high-quality queries to solve customer problems [17] and determines success or failure in purchasing behaviors through positive verbal and nonverbal human-computer interaction [16].

Chatbot (also known as the conversational agent) can be considered a kind of ICS that exploits natural language technologies to engage users in informationseeking and task-oriented dialogue [40]. It usually has a special photo sticker, a name, and a kind of human speaking style. It has been integrated into social media messaging applications such as Facebook, LINE, etc. Traditional chatbot is rule-based, which only respond to users through pre-set dialogue menus to complete specific tasks. Nowadays, the growth of chatbot services depends on the advancement in AI, NLP, and chatbot development platforms [53], along with the rising demand for self-service. AI-based chatbot can communicate like a real person because they have continuous learning capability and gain effective information. In this paper, we focus on AI-based text chatbot, which enable interaction with humans through natural written language.

\subsection{Cognitive stage}

2.2.1. Chatbot-ICS quality (ICSQ). The information system (IS) success model has been used to examine the effectiveness of information systems and their impact on users [20]. This model considers system quality and information quality as two major antecedents of system satisfaction and usage. System quality refers to the fineness of characteristics the IS has. For many information systems, the hardware facilities or accessibility of the system are the most basic and important for users. The performance of system quality is an essential factor for users to develop high satisfaction [19]. Information quality refers to the fineness of content features provided to users by IS. Whether the system can provide complete or accurate information to users will affect users' satisfaction of the information system. Similar to system quality, information quality is used in many fields. A decade later, another component, service quality, was added as the third quality factor in an e-Commerce context [20]. Service quality has a solid literature foundation in terms of relationship marketing or information system satisfaction [33]. Since 1985, much literature has appeared one after another mentioning the measurement of service quality. SERVQUAL [50] used five variables for an extension to be a service quality questionnaire. Later, this research has gradually become the standard of measuring service quality. Brady and Cronin [10] measured 
service quality by dividing it into three sub-constructs: interaction quality, physical environment quality, and out-come quality.

In fact, various quality factors have been proposed to understand the quality of a specific system or service, such as website quality [62] and social commerce quality [3, 35]. With the advancement of AI and its implementation in the customer service area, there is a need to define the quality of service offered by AI-empowered systems. Based on the literature review and the Delphi method, Wen [63] extended the IS success model and constructed the dimensions of ICSQ. In addition to system quality and information quality, two additional components were identified. Intelligent quality refers to the degree that IS can understand the user's problems, use the information it has to search for relevant answers, and continue to strengthen and correct. For intelligent customer service, it is very important for users to provide sufficient and useful information. Since AI contains learning capability and is expected to be smart, some features need to be added. We therefore proposed another quality index. Interaction quality refers to the degree that IS can interact with users in a human-like way. The concept of interaction quality is mainly adopted from service quality. For interaction quality, this component focuses on whether the AI-empowered system can act like a human being and interact with the users politely. Given that chatbot-ICS is empowered by AI which keeps on learning and improving based on the previous information like a real person. Whether this system can know how to effectively understand the question asked by users and provide adequate answers is critical.

2.2.2. Anthropomorphism. Anthropomorphism is defined as the tendency to imbue the real or imagined behavior of nonhuman agents with humanlike characteristics, motivations, intentions, or emotions [22]. Anthropomorphism can be traced back to 1995 and has been applied to a range of contexts that include product [36], brand [41], advertising [57], etc. Recently, this idea has been discussed in intelligent customer service $[1,25,41]$.

There are commonly discussed three cues to suggest anthropomorphism among online customer service: visual, identity, and conversational [25]. First, visual cues reflect the extent to which the inanimate object looks like a human. It is usually tested by human-like shape versus nonhuman shape [58] or the degree of human shape [21] because visual cues may inspire people's "humanness heuristics" and interact socially with them $[25,56]$. Second, identity cues reflect the extent to which a user feels an inanimate object's uniqueness [1]. It is usually manipulated by humanassociated names and talking in first-person $[36,52]$ because human identity cues will trigger people to evaluate the agent's performance based on their criteria or expectation of humans $[25,56]$. Third, conversational cues reflect the inanimate object and have distinctive thoughts by expressing its messages [8]. It is usually produced by mimicking human languages or responding to the message in a back-and-forth fashion in the experiment because conversational cues will make the full message interactivity and show an awareness of the previous conversation like a human $[25,56]$.

Chatbot has been so well integrated into the ICS during the past years that customers hardly distinguish whether they are interacting with a human or a robot. According to previous research, anthropomorphism influences users' feelings directly [64]. When people talk to a more human-like chatbot-ICS, they sense a higher level of interactive [48] and social presence [1, 25]. Since interaction quality and intelligent quality focus on the degree that chatbot-ICS can act like a real person when interacting with customers. Therefore, we hypothesize the following.

H1: Anthropomorphism has a positive effect on ICSQ.

\subsection{Affective stage}

2.3.1. Chatbot-ICS identity (ICS identity). The concept of IT identity has been highlighted as one critical driver of extended usage [11]. IT identity refers to the extent to which an individual views the use of an IT as integral to his or her sense of self [11]. Therefore, we consider ICS identity as the extent to which customers consider the use of a chatbot-ICS as part of themselves. Following the definition proposed by Carter and Grover [11], we also consider ICS identity should contain three interrelated dimensions: relatedness, emotional energy, and dependence. First, relatedness represents the blurring of boundaries between the self and a chatbot-ICS and manifests as feelings of connectedness with the chatbot-ICS. Second, emotional energy refers to a person's enduring feelings of emotional attachment and enthusiasm in relation to a chatbot-ICS. Third, dependence captures a person's sense of reliance upon a chatbot-ICS.

When chatbot are more anthropomorphic, it is easier for users to build connections with them. Ameen, et al. [4] mentioned that the relationship is a kind of relatedness. Hildebrand and Bergner [31] found that conversational robot advisors positively influence benevolence, recommendation, and acceptance. Since chatbot is one type of conversational robot, users can also likely generate strong belongingness after using chatbot-ICS. Furthermore, different from interacting with traditional click and select style 
systems, surprising answers amuse users. Users are excited when they use the chatbot-ICS. Finally, since chatbot-ICS can learn and evolve gradually, the problems that chatbot-ICS can solve, or answer are much more than a traditional online customer service system. Therefore, customers are relying more on chatbot-ICS to solve their problems. Therefore, we hypothesize the following.

$\mathrm{H} 2$ : Anthropomorphism has a positive impact on ICS identity.

ICSQ contains four dimensions: system quality, information quality, intellectual quality, and interaction quality. When a chatbot is more mature, those four quality indexes are higher. High system quality indicates that a chatbot-ICS is robust and reliable. High information quality represents that the information offered by chatbot-ICS is timely and precise. A high intelligent quality chatbot-ICS can effectively understand users' questions and provide appropriate answers. Users are more dependent on the chatbot-ICS to answer more questions precisely and solve more problems effectively. Lastly, while interacting with a high interaction quality chatbot-ICS, users feel that they are interacting with a real person. It is easier for users to sense relatedness with the chatbot-ICS. Chenet, et al. [14] proved that service quality affects commitment indirectly, which is similar to IT identity. The above arguments indicate that users of a chatbotICS develop a higher identity when the chatbot-ICS is in high quality. Thus, we hypothesize the following.

H3: ICSQ has a positive impact on ICS identity.

2.3.2. Satisfaction. Satisfaction refers to overall contentment with utilizing a service or product or with the system usage experience [18]. It plays a critical role in the IS success model, and empirical studies have indicated that information quality and system quality can positively affect user satisfaction [51].

Previous research has shown that virtual agents can enhance user satisfaction in various contexts [16, 33]. Chatbot can process efficiently and provide accurate and convenient information that is positively linked to user satisfaction [39]. On the contrary, users may be dissatisfied with the system if system features cannot achieve their specific goals via the internet [59]. Furthermore, if chatbot can emphasize user's interest topics and provide the information they expect, the technology is satisfactory [2]. Therefore, we hypothesize the following.

H4: ICSQ has a positive effect on satisfaction.

Additionally, Blut, et al. [9] assumed that when the robot has more human-like characteristics, anthropomorphism can inspire people's perceptions, evaluations, and relationships with a robot. Lee, et al. [41] also found that small talk influenced chatbot self-disclosure and positively affected participants' perceived intimacy and enjoyment. Go and Sundar [25] have indicated personalization enhances customer experience. Hence, we assume anthropomorphism will influence satisfaction because its appearance makes the customer feel intimate and friendly speaking makes the customer feel harmonious. Therefore, we hypothesize the following.

H5: Anthropomorphism has a positive effect on satisfaction.

\subsection{Behavioral stage}

2.4.1. Usage. Usage refers to users' intention to continue using chatbot-ICS [7]. User satisfaction is a key antecedent of continuance intention, which has been broadly studied in marketing and information system literature [7, 34]. A few studies have also illustrated this relationship in different contexts. For instance, extending the DeLone and McLean model of IS success in the e-commerce context, Wang [61] found intention to reuse is affected by satisfaction, which, in turn, are influenced by information quality, system quality, and service quality. Similarly, the more satisfied with the online shopping experience, the greater the level of online repurchase intention [54]. The relationship between satisfaction and continuance intention also can be found in the computer-support context [60]. If customers are pleased with their intelligent customer service experience, they would be more motivated to continue using such chatbot. Therefore, we hypothesize the following.

H6: Satisfaction has a positive effect on usage.

ICS identity means the customer has a deep affection for using chatbot-ICS, and the customer desires to use chatbot-ICS deeply in the long term [49]. Previous research has illustrated that identity is the primary motivator of a set of behaviors and mentioned that IT identity influences the use and feature usage[11]. Esmaeilzadeh [23] has indicated that IT identity affects a user to have extra usage, representing a user improving IT to have a better quality of IT. Thus, we hypothesis

H7: ICS identity has a positive effect on usage.

2.4.2. Customer citizenship behaviors (CCB). CCB are defined as voluntary and discretionary behaviors that are not required for the successful production or delivery of the service but that, in the aggregate, help the service organization overall [27]. Groth [27] has identified three dimensions of CCB: First, providing feedback means that customers voluntarily provide suggestions to the company for product or service improvement. Second, helping other customers implies 
that customers can assist other company's customers through their activities to contribute to their perceptions of the quality of the firm's offerings. Third, recommendation indicates an advocate customer recommends the company by a positive word of mouth.

Although current chatbot is used for individuals to interact with AI, CCB does not occur only when people use the service. For example, during a chat, a friend mentioned that customer service calls often have to wait long before a customer service staff can provide service. Customers who have used smart customer service in the past can make recommendations and tell friends where and how to use related services at this time. When customers are in the process of using, if they find that chatbot has any function that needs improvement, they may also give relevant feedback for the company to use as a reference for optimization.

Prior research has consistently linked user satisfaction to CCB. Groth [27] found customer satisfaction is an antecedent of customer citizenship behaviors. In the e-commerce context, familiarity with an estore and facilitating conditions provided by an e-retailer can drive customer satisfaction [5]. If customers are satisfied with the service quality and the information quality of the community, they will engage in citizenship behaviors [13]. Anaza [6] indicated that customer satisfaction influences CCB in online shopping situations. Gong, et al. [26] also proved when a customer is passionate and excited about using selfcheck, it influences CCB positively. Accordingly, we hypothesize:

H8: Satisfaction has a positive effect on CCB.

Based on the social identity theory, identification fulfills the need of an individual for social identity and self-definition [43]. When customers have a strong brand community identity, they may seek to continue this relationship with their CCB [44]. Recently, more and more scholars focus on the identification of material objects such as IT identity. In this study, we assume that when users have a highly ICS identity with chatbot, they will form attachments to the company and recommend the company to family and friends, help other customers with their needs, and provide feedback to the company. Thus, we hypothesis:

H9: ICS identity has a positive effect on CCB.

\section{Research method}

\subsection{Construct and Measurement}

To test the proposed hypotheses, a survey approach was adopted. We adapted multi-item scales from prior studies for the measurement of variables wherever possible. All constructs were measured with 7-point Likert scales ranging from "strongly disagree", (1) to "strongly agree", (7).

Table 1 Constructs, measurements, and factor loadings

\begin{tabular}{|c|c|c|}
\hline Constructs & Measurement items & Loading \\
\hline \multirow{5}{*}{$\begin{array}{l}\text { Anthropomorphism (PA) } \\
\text { : CR: } 0.93 \\
\text { AVE: } 0.74 \\
\text { Reference: }[32,45,47]\end{array}$} & $\begin{array}{l}\text { 1. The intelligent customer service is able to } \\
\text { speak like a human. }\end{array}$ & 0.83 \\
\hline & $\begin{array}{l}\text { 2. The inteliligent customer service's photo is } \\
\text { like a human. }\end{array}$ & 0.91 \\
\hline & $\begin{array}{l}\text { 3. The intelligent customer service's photo is } \\
\text { lifelike. }\end{array}$ & 0.91 \\
\hline & $\begin{array}{l}\text { 4. Ifeel the intelligent customer service is realis- } \\
\text { tic. }\end{array}$ & 0.87 \\
\hline & $\begin{array}{l}\text { 5. Ifeel the intelligent customer service is not } \\
\text { machinelike. }\end{array}$ & 0.78 \\
\hline \multirow{4}{*}{$\begin{array}{l}\text { System quality (SQ) } \\
\text { CR: .0.90 } \\
\text { AVE: } 0.70 \\
\text { Peference: }[20,46,63]\end{array}$} & $\begin{array}{l}\text { 1. The intelligent customer service performs reli- } \\
\text { ably. }\end{array}$ & 0.84 \\
\hline & $\begin{array}{l}\text { 2. The intelligent customer sevice returns an- } \\
\text { swers to my requests quickly. }\end{array}$ & 0.82 \\
\hline & 3. The intelligent customer service is easy to use. & 0.87 \\
\hline & $\begin{array}{l}\text { 4. The user interface of the intelligent customer } \\
\text { service is simple and clear. }\end{array}$ & 0.80 \\
\hline \multirow{4}{*}{$\begin{array}{l}\text { Information quality (IFQ) } \\
\text { : CR: } 0.90 \\
\text { AVE: } 0.70 \\
\text { - Reference: }[24,46]\end{array}$} & $\begin{array}{l}\text { 1. The intelligent customer service provides me } \\
\text { a complete set of information. }\end{array}$ & 0.82 \\
\hline & $\begin{array}{l}\text { 2. The intelligent customer service provides a } \\
\text { personalized information presentation. }\end{array}$ & 0.89 \\
\hline & $\begin{array}{l}\text { 3. The intelligent customer service provides up- } \\
\text { to- date information. }\end{array}$ & 0.79 \\
\hline & $\begin{array}{l}\text { 4. The intelligent customer service provides in- } \\
\text { formation that is easy to understand. }\end{array}$ & 0.85 \\
\hline \multirow{3}{*}{$\begin{array}{l}\text { Intelligent quality (INTQ) } \\
\text { CR: : } 0.91 \\
\text { AVE: } 0.77 \\
\text { Reference: [63] }\end{array}$} & $\begin{array}{l}\text { 1. The intelligent customer service understands } \\
\text { my question and can find relevant answers. }\end{array}$ & 0.89 \\
\hline & $\begin{array}{l}\text { 2. The intelligent customer service provides in- } \\
\text { formation according to previous context that } \\
\text { is relevant to your needs. }\end{array}$ & 0.87 \\
\hline & $\begin{array}{l}\text { 3. The intelligent customer service can answer } \\
\text { questions in the professional field. }\end{array}$ & 0.87 \\
\hline \multirow{2}{*}{$\begin{array}{l}\text { Interaction quality (ITAQ) } \\
\text { CR: } 0.87 \\
\text { AV: } 0.78 \\
\text { - Reference: [63] }\end{array}$} & $\begin{array}{l}\text { 1. When } 1 \text { have a problem, the intelligent cus- } \\
\text { tomer service shows a sincere interest in solv- } \\
\text { ing it. }\end{array}$ & 0.90 \\
\hline & $\begin{array}{l}\text { 2. The intelligent customer service understands } \\
\text { my specific needs. }\end{array}$ & 0.87 \\
\hline \multirow{5}{*}{$\begin{array}{l}\text { ICS identity (ICSD) } \\
\text { : CR:0.97 } \\
\text { AVE: } 0.84 \\
\text { Reference: [12] }\end{array}$} & $\begin{array}{l}\text { 1. Thinking about myself in relation to intelli- } \\
\text { gent customer service, }\end{array}$ & 0.92 \\
\hline & $\begin{array}{l}\text { 2. Iam dependent on intelligent customer ser- } \\
\text { vice. }\end{array}$ & 0.92 \\
\hline & 3. a am reliant on intelligent customer service. & 0.94 \\
\hline & $\begin{array}{l}\text { 4. Tam energized: } \\
\text { 5. Tam enthusiastic. }\end{array}$ & $\begin{array}{l}0.90 \\
0.89\end{array}$ \\
\hline & 6. I am linked with intelligent customer service. & 0.93 \\
\hline \multirow{3}{*}{$\begin{array}{l}\text { Satisfaction (SAT) } \\
\text { : CR: } 0.96 \\
\text { AVE: } 0.90 \\
\text { A Reference: [38] }\end{array}$} & $\begin{array}{l}\text { 1. } \text { am generally pleased with the intelligent } \\
\text { customer service. }\end{array}$ & 0.92 \\
\hline & $\begin{array}{l}\text { "2. Tam very satisfied with the intelligent cus- } \\
\text { tomer service services }\end{array}$ & 0.97 \\
\hline & $\begin{array}{l}\text { "I. I am happy with the intelligent customer ser- } \\
\text { vice }\end{array}$ & 0.96 \\
\hline \multirow{3}{*}{$\begin{array}{l}\text { Usage (US) } \\
\text { :CR: } 0.93 \\
\text { : AVE: } 0.81 \\
\text { Reference: [7] }\end{array}$} & $\begin{array}{l}\text { 1. Tintend to continue using the intelligent cus- } \\
\text { tomer service rather than discontinue its use }\end{array}$ & 0.93 \\
\hline & $\begin{array}{l}\text { 2. My intentions are to continue using the intelli- } \\
\text { gent customer service than use any alternative } \\
\text { means (going to the bank). }\end{array}$ & 0.85 \\
\hline & $\begin{array}{l}\text { 3. I would like to discontinue my use of intelli- } \\
\text { gent customer service. }\end{array}$ & 0.92 \\
\hline \multirow{3}{*}{$\begin{array}{l}\text { Providing feedback (CCBF) } \\
\text { CR: 0. } 95 \\
\text { AVE: } 0.85 \\
\text { - Reference: [27] }\end{array}$} & $\begin{array}{l}\text { 1. Recommend the intelligent customer service } \\
\text { to your family who are the customers of this } \\
\text { bank. }\end{array}$ & 0.92 \\
\hline & $\begin{array}{l}\text { 2. Recommend the intelligent customer service } \\
\text { to your peers who are the customers of this } \\
\text { bank. }\end{array}$ & 0.92 \\
\hline & $\begin{array}{l}\text { 3. Recommend the intelligent customer service } \\
\text { to people interested in this bank. }\end{array}$ & 0.93 \\
\hline \multirow{3}{*}{$\begin{array}{l}\text { Helping other customers } \\
\text { (CCBH) } \\
\text { : CR: } 0.96 \\
\text { : AVE: } 0.89 \\
\text { - Reference: }[27]\end{array}$} & $\begin{array}{l}\text { 1. Assist other customers in finding the intelli- } \\
\text { gent customer service. }\end{array}$ & 0.94 \\
\hline & $\begin{array}{l}\text { 2. Teach someone how to use the intelligent cus- } \\
\text { tomer service. }\end{array}$ & 0.94 \\
\hline & $\begin{array}{l}\text { 3. Assist other customers to solve their problems } \\
\text { in using smart customer service. }\end{array}$ & 0.94 \\
\hline \multirow{3}{*}{$\begin{array}{l}\text { Recommendation (CCBR) } \\
\text { CR: } 0.98 \\
\text { AVE: } 0.93 \\
\text { A Reference: [27] }\end{array}$} & $\begin{array}{l}\text { 1. Fill out a customer satisfaction survey about } \\
\text { intelligent customer service. }\end{array}$ & 0.97 \\
\hline & $\begin{array}{l}\text { 2. Provide helpful feedback to intelligent cus- } \\
\text { tomer service. }\end{array}$ & 0.97 \\
\hline & $\begin{array}{l}\text { 3. Provide information when surveyed by the } \\
\text { telligent customer service. }\end{array}$ & 0.95 \\
\hline
\end{tabular}

The operational definitions and measurements of each construct are shown in Table 1. For the behavioral stage, usage refers to customers' intention to continue to use chatbot-ICS. Three items adapted from [7] were used to capture the extent to which customers want to keep using chatbot-ICS. CCB are treated as a second-order formative construct that contains three first-order constructs: feedback, help, recommendation. We measure CCB adapted form [31]. Since the three constructs are reflective, the three constructs are measured by three items respectively. 
For the affective stage, satisfaction refers to users' feelings about the use of chatbot-ICS. Three items were adopted from [38] to measure the extent to which customers are satisfied and content with the chatbotICS. ICS identity refers to the extent to which an individual views the use of a chatbot-ICS as integral to his or her sense of self. Totally six items were adopted from [11] to respectively capture customer's relatedness, emotional energy, and dependence on chatbotICS.

For the cognitive stage, ICSQ refers to customers' perception of chatbot-ICS, and it is treated as a secondorder reflective construct that contains system quality (SQ), information quality (IFQ), intelligent quality (INTQ), interaction quality (ITAQ). Four items used to measure SQ include the system tangibles, reliability, response time, and ease of use. Four items used to measure IFQ are completeness, accuracy, timeliness, and ease of understanding of the provided information. Three items used to measure INTQ cover intellectual level, perceived expertise, and consecutiveness of two answers. Three items used to measure ITAQ focused on courtesy, assurance, and empathy during the interaction. Anthropomorphism (PA) refers to the tendency to imbue the real or imagined behavior of chatbot-ICS with humanlike characteristics, motivations, intentions, or emotions [22]. We use a total of 5 question items to measure. Items 1 adapted from [45] and items $2,3,4,5$ adapted from [32] to respectively measure the visual, identity, and conversational cues of PA in ICS.

\subsection{Samples}

To fulfill our research purpose, the target sample was individuals who have experience with ICS. First, we translated English items into Chinese because we investigated in Taiwan. Second, we did a pre-test with 4 experts with chatbot-ICS experience to get suggestions and revised some items by adjusting Chinese semantics. Third, a pilot study with $27 \mathrm{MBA}$ students who had chatbot-ICS experience was also conducted.

Table 2 The demographic of the respondents $(n=183)$

\begin{tabular}{|c|c|c|c|c|c|c|c|}
\hline Measure & Categories & \# & $\%$ & Measure & Categories & \# & $\%$ \\
\hline \multirow{2}{*}{ Gender } & Male & 94 & 51.37 & \multirow{7}{*}{$\begin{array}{l}\text { Work in- } \\
\text { dustry }\end{array}$} & Student & 25 & 13.66 \\
\hline & Female & 89 & 48.63 & & Finance & 13 & 7.10 \\
\hline \multirow{6}{*}{$\begin{array}{l}\text { Age } \\
\text { (year) }\end{array}$} & $<21$ & 7 & 3.83 & & Manufacturing & 33 & 18.03 \\
\hline & $21-30$ & 64 & 34.97 & & $\begin{array}{l}\text { Information } \\
\text { technology }\end{array}$ & 53 & 28.96 \\
\hline & $31-40$ & 50 & 27.32 & & $\begin{array}{l}\text { Government and } \\
\text { institution }\end{array}$ & 28 & 15.20 \\
\hline & $41-50$ & 49 & 26.78 & & Service & 24 & 13.11 \\
\hline & $51-60$ & 13 & 7.10 & & Others & 7 & 3.83 \\
\hline & & & & \multirow{5}{*}{$\begin{array}{l}\text { Frequency } \\
\text { of using } \\
\text { chatbot- } \\
\text { ICS }\end{array}$} & Very low & 28 & 15.30 \\
\hline \multirow{4}{*}{ Education } & High school & 4 & 2.19 & & Low & 70 & 38.25 \\
\hline & College & 82 & 44.81 & & Medium & 56 & 30.60 \\
\hline & Master's & 93 & 50.82 & & High & 24 & 13.11 \\
\hline & Doctoral & 4 & 2.19 & & Very high & 5 & 2.73 \\
\hline
\end{tabular}

Finally, we conducted an online survey and posted it on a famous forum (PTT) in Taiwan. Data collection ran from March to May 2021. A total of 255 individuals took the online survey. After excluding 72 incomplete responses, there were 183 responses collected. The demographic data for our sample are shown in Table 2.

\subsection{Reliability and validity}

The measurement model relating the scale items to their latent constructs was analyzed using SmartPLS 3.0. In our study, chatbot-ICSQ was treated as a reflective second-order construct dependent variable and CCB was treated as a formative second-order construct dependent variable. Table 1 shows the composite reliability (CR), the average variance extracted (AVE) and factor loadings. The composite reliability values for all constructs were above the recommended level of 0.70 , indicating adequate internal consistency.

Table 3 Correlations among constructs and the square root of AVE

\begin{tabular}{|c|c|c|c|c|c|c|c|c|c|c|c|c|}
\hline & onstructs & 1 & 2 & 3 & 4 & 5 & 6 & 7 & 8 & 9 & 10 & 11 \\
\hline & 1. PA & 0.86 & & & & & & & & & & \\
\hline \multirow{7}{*}{ ICSQ } & 2. $S Q$ & 0.37 & 0.83 & & & & & & & & & \\
\hline & 3. IFQ & 0.45 & 0.73 & 0.84 & & & & & & & & \\
\hline & 4. INTQ & 0.49 & 0.58 & 0.75 & 0.88 & & & & & & & \\
\hline & 5. ITAQ & 0.51 & 0.54 & 0.65 & 0.68 & 0.88 & & & & & & \\
\hline & 6. ICSD & 0.70 & 0.48 & 0.55 & 0.60 & 0.63 & 0.92 & & & & & \\
\hline & 7. SAT & 0.56 & 0.65 & 0.72 & 0.71 & 0.66 & 0.76 & 0.95 & & & & \\
\hline & 8. US & 0.51 & 0.55 & 0.64 & 0.59 & 0.57 & 0.77 & 0.78 & 0.90 & & & \\
\hline \multirow{3}{*}{$\mathrm{CCB}$} & 9. $\mathrm{CCBF}$ & 0.33 & 0.27 & 0.33 & 0.18 & 0.30 & 0.35 & 0.38 & 0.33 & 0.92 & & \\
\hline & 10. CCBH & 0.46 & 0.40 & 0.41 & 0.44 & 0.44 & 0.58 & 0.63 & 0.65 & 0.53 & 0.94 & \\
\hline & 11. CCBR & 0.46 & 0.51 & 0.57 & 0.58 & 0.52 & 0.62 & 0.71 & 0.74 & 0.39 & 0.77 & 0.96 \\
\hline
\end{tabular}

Table 4 Heterotrait-monotrait ratio (HTMT)

\begin{tabular}{|c|c|c|c|c|c|c|c|c|c|c|c|c|}
\hline \multicolumn{2}{|c|}{ Constructs } & 1 & 2 & 3 & 4 & 5 & 6 & 7 & 8 & 9 & 10 & 11 \\
\hline \multicolumn{13}{|c|}{ 1. $\mathrm{PA}$} \\
\hline \multirow{7}{*}{ ICSQ } & 2. SQ & 0.41 & & & & & & & & & & \\
\hline & 3. IFQ & 0.51 & 0.85 & & & & & & & & & \\
\hline & 4. INTQ & 0.56 & 0.66 & 0.86 & & & & & & & & \\
\hline & 5. ITAQ & 0.65 & 0.68 & 0.83 & 0.86 & & & & & & & \\
\hline & 6. ICSD & 0.74 & 0.52 & 0.60 & 0.66 & 0.77 & & & & & & \\
\hline & 7. SAT & 0.61 & 0.72 & 0.80 & 0.78 & 0.81 & 0.80 & & & & & \\
\hline & 8. US & 0.57 & 0.62 & 0.74 & 0.68 & 0.72 & 0.84 & 0.85 & & & & \\
\hline \multirow{3}{*}{$\mathrm{CCB}$} & 9. $\mathrm{CCBF}$ & 0.36 & 0.30 & 0.37 & 0.20 & 0.37 & 0.37 & 0.40 & 0.35 & & & \\
\hline & $10 . \mathrm{CCBH}$ & 0.49 & 0.44 & 0.46 & 0.49 & 0.54 & 0.61 & 0.67 & 0.71 & 0.56 & & \\
\hline & 11. CCBR & 0.49 & 0.56 & 0.63 & 0.64 & 0.63 & 0.65 & 0.74 & 0.80 & 0.41 & 0.81 & \\
\hline
\end{tabular}

In addition, convergent and discriminant validity should be tested when multiple indicators are used to measure one construct and can be examined by factor loadings and AVE by constructs. To have the required convergent validity, factor loadings should be greater than 0.70, and AVE should be greater than 0.50. For our model, all loadings were above 0.7, and AVE ranged from 0.61 to 0.93 (see Table 1). Thus, both conditions for convergent validity were met. To achieve adequate discriminant validity, the correlation between pairs of constructs should be less than 0.90 , and 
the square root of AVE should be greater than the inter-construct correlation coefficients. As shown in Table 3, all the diagonal values exceeded the inter-construct correlations. Additionally, we employed the heterotrait-monotrait (HTMT) ratio of correlations, to further check the degree to which the latent variables (constructs) are distinctly different. The HTMT should be lower than 0.90 [30]. As Table 4 shows, all HTMT values are lower than 0.90 .

\subsection{Hypothesis testing}

The measurement model was shown in Figure 1. The path from PA to chatbot-ICSQ is significant, H1 is supported. Chatbot-ICSQ is affected by PA ( $\beta=$ 0.538 , p-value $<0.001)$. All paths between cognitive variables and affective variables are significant. ICS identity is affected by both PA $(\beta=0.480$, p-value < $0.001)$ and chatbot-ICSQ $(\beta=0.406$, $p$-value $<0.001)$. Satisfaction is affected by both PA $(\beta=0.187$, p-value $<0.001)$ and chatbot-ICSQ $(\beta=0.697, \mathrm{p}$-value < $0.001)$. Besides, PA and chatbot-ICSQ collaboratively explain $66.1 \%$ of the variance of satisfaction, and $60.5 \%$ of the variance of ICS identity. Therefore, H2H5 are all supported. We found all links between affective variables and behavioral variables are significant. Usage is affected by both satisfaction $(\beta=0.443$, p-value $<0.001)$ and ICS identity $(\beta=0.438$, p-value $<0.001)$. CCB are affected by both satisfaction $(\beta=$ 0.545 , p-value $<0.001)$ and ICS identity $(\beta=0.233$, pvalue $<0.001)$. In addition, satisfaction and ICS identity explain $68.2 \%$ of the variance of usage, and $54.3 \%$ of the variance of CCB. Hence, H6-H9 are all supported.

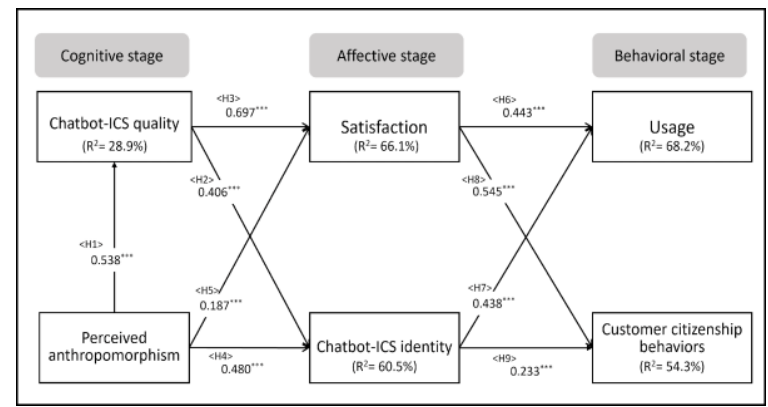

Figure 1 Path analysis.

\section{Discussion}

As the result showed, anthropomorphism influences ICSQ. One component of ICSQ, interaction quality, focuses on the extent to which chatbot-ICS acts like a human being in the interaction process. The components of interaction quality contain curtsey, em- pathy, and assurance. On the other hand, the components of intelligent quality contain intelligence and expertise. Those components make chatbot-ICS perceived more like a human being for customers. Therefore, the coefficient between anthropomorphism and ICSQ is very strong and significant.

For satisfaction and ICS identity, while satisfaction is more affected by ICSQ $(\beta=0.697$ for ICSQ; $\beta=0.187$ for anthropomorphism), ICS identity is more associated with anthropomorphism $(\beta=0.406$ for ICSQ; $\beta=0.480$ for anthropomorphism). As indicated above, satisfaction is determined by the quality of service that chatbot-ICS can offer, instead of whether chatbot-ICS looks or acts like a human being. Aligning with past studies that service quality is highly associated with satisfaction, satisfaction is mainly determined by ICSQ. Surprisingly, ICS identity is associated with anthropomorphism. However, since identity can be considered as associating self with the target, whether the target is vivid to connect oneself with is critical. Identity contains three components: relatedness, emotional energy, and dependence. Users are more likely to feel emotionally energized when they interact with a human-like system. It is easier for individuals to relate to the system when it has a nickname, a human-like picture, and can communicate like a real person.

For the behavioral stage, both usage and customer citizenship behaviors are associated with satisfaction and ICS identity. The impact of satisfaction on two behavioral outcomes $(\beta=0.443$ for usage; $\beta=0.545$ for $\mathrm{CCB})$ is significant and similar to identity $(\beta=0.438$ for usage; $\beta=0.233$ for $\mathrm{CCB}$ ). Past study pointed out that usage is more affected by satisfaction [38]. In this study, ICS identity has been shown to play a role similar to satisfaction in an online customer service context. Our results highlight the importance of making the chatbot-ICS appear and act like a human being. Interacting with a human-like online customer system allows users to build identity with the systems, which, in turn, encourages further use and promotes altruistic behaviors.

\subsection{Implications for academia}

This study generates several contributions to according research streams. First, for online customer service research, we are one of the pioneers to explore AI-empowered customer service systems. We specifically focused on the chatbot system and highlighted the importance of creating anthropomorphism for this system. A human-like system can enhance perceived quality, increase satisfaction, and build user identity. Second, this study also contributes to anthropomorphism study. Past anthropomorphism studies mainly 
focus on its impact on social presence, intimacy, or emotional feeling. This study extends this research stream by showing the impact of anthropomorphism not only on short-term perception (quality) and emotion (satisfaction) but also only long-term emotion (identity). Third, for IT identity study, this study shows other possible antecedents and consequences of IT identity. Past studies consider investment and satisfaction as major antecedents of identity. This study also shows that anthropomorphism building a humanlike system - can help construct users' identity. In addition, for the consequence of identity, past studies only consider various types of usage. In this study, we added customer citizenship as another possible outcome of identity. Future research may further explore other possible outcomes of high identity. Fourth, we illustrated that satisfaction is more associated with quality while identity is more affected by anthropomorphism. On the other hand, identity has a stronger impact than satisfaction, on both usage and citizenship behavior. Even though the critical role of satisfaction has been highlighted in the past, this study sheds light on this area by showing that identity is more associated with behaviors.

\subsection{Implications for practitioners}

Our research generates three implications for practitioners. First, anthropomorphism is critical for lifting service quality, increasing satisfaction, and fostering identity. Even though many organizations present their chatbot with a nickname high identity me and human-like avatar, some organizations still choose a robot style appearance for their chatbot. We recommend those organizations change the appearance of their chatbot to a human-like style. In addition, users sense a higher level of anthropomorphism if the system can use human-like language to interact with them. In this condition, more positive benefits can be expected.

In addition, we also recommend organizations foster identity toward their intelligent customer service system. This can be done by increasing anthropomorphism directly. It can also be done by increasing the quality of chatbot-ICS. A better quality system can definitely lead to higher satisfaction, an important antecedent of ISS identity.

Even though organizations that adopt chatbot-ICS should promote the system actively, satisfied customers are another important but free means to facilitate promotion. Satisfied customers are more willing to use the system again and encourage and help other users to use the system. The major approach to increase satisfaction is to improve the quality of the chatbot-ICS. In addition to building a reliable system that can offer adequate and precise information, whether the system is smart enough and can interact like real service personnel is critical. Lastly, building identity is also critical since it leads to both usage and citizenship behaviors. chatbot-ICS users are more connected with chatbot-ICS when chatbot-ICS looks and acts like a real person.

\subsection{Limitation}

This study is not without limitations. First, there are different AI chatbot customer service types, including text, voice, and robot. In this research, we only conduct research on text-based AI customer service of text-based. Therefore, the results of this research may not be able to fully explain the AI customer service of voice and robot. It is suggested that future research can compare the similarities and differences of different types of ICS. Second, cross-sectional data were used to examine the proposed model. Further research is recommended to adopt a longitudinal approach to address this issue. Third, the data for this study only comes from a single culture in Taiwan. It is recommended that future research can collect data from different cultures for a more comprehensive understanding.

\section{References}

[1] Adam M., Wessel M., and Benlian A., "AI-based chatbots in customer service and their effects on user compliance," Electronic Markets, pp. 1-19, 2020.

[2] Akhtar M., Neidhardt J., and Werthner H., "The potential of chatbots: analysis of chatbot conversations," in 2019 IEEE 21st Conference on Business Informatics (CBI), 2019, vol. 1, pp. 397-404: IEEE.

[3] Aladwani A. M., "A quality-facilitated socialization model of social commerce decisions," International Journal of Information Management, vol. 40, pp. 1-7, 2018.

[4] Ameen N., Tarhini A., Reppel A., and Anand A., "Customer experiences in the age of artificial intelligence," Computers in Human Behavior, vol. 114, p. 106548, 2020.

[5] Anaza N. A. and Zhao J., "Encounter-based antecedents of e-customer citizenship behaviors," Journal of Services Marketing, 2013.

[6] Anaza N. A., "Personality antecedents of customer citizenship behaviors in online shopping situations," Psychology \& Marketing, vol. 31, no. 4, pp. 251-263, 2014.

[7] Bhattacherjee A., "Understanding information systems continuance: An expectation-confirmation model," MIS quarterly, pp. 351-370, 2001.

[8] Bilgihan A., Kandampully J., and Zhang T. C., "Towards a unified customer experience in online 
shopping environments," International Journal of Quality and Service Sciences, 2016.

[9] Blut M., Wang C., Wünderlich N. V., and Brock C., "Understanding anthropomorphism in service provision: A meta-analysis of physical robots, chatbots, and other AI," Journal of the Academy of Marketing Science, pp. 1-27, 2021.

[10] Brady M. K. and Cronin J. J. J., "Some new thoughts on conceptualizing perceived service quality: a hierarchical approach," Journal of marketing, vol. 65, no. 3, pp. 34-49, 2001.

[11] Carter M. and Grover V., "Me, my self, and I (T) conceptualizing information technology identity and its implications," Mis Quarterly, vol. 39, no. 4, pp. 931958, 2015.

[12] Carter M., Petter S., Grover V., and Thatcher J. B., "Information Technology Identity: A Key Determinant of IT Feature and Exploratory Usage," MIS Quarterly, vol. 44, no. 3, 2020.

[13] Chen M.-J., Chen C.-D., and Farn C.-K., "Exploring determinants of citizenship behavior on virtual communities of consumption: The perspective of social exchange theory," International Journal of Electronic Business Management, vol. 8, no. 3, p. 195, 2010.

[14] Chenet P., Dagger T. S., and O'Sullivan D., "Service quality, trust, commitment and service differentiation in business relationships," Journal of services Marketing, 2010.

[15] Christopher M., Payne A., and Ballantyne D., "Relationship marketing: bringing quality customer service and marketing together," 1991.

[16] Chung M., Ko E., Joung H., and Kim S. J., "Chatbot eservice and customer satisfaction regarding luxury brands," Journal of Business Research, vol. 117, pp. 587-595, 2020.

[17] Cui L., Huang S., Wei F., Tan C., Duan C., and Zhou M., "Superagent: A customer service chatbot for ecommerce websites," in Proceedings of ACL 2017, System Demonstrations, 2017, pp. 97-102.

[18] Cyr D., "Modeling web site design across cultures: relationships to trust, satisfaction, and e-loyalty," Journal of management information systems, vol. 24, no. 4, pp. 47-72, 2008.

[19] DeLone W. H. and McLean E. R., "Information Systems Success: The Quest for the Dependent Variable," (in English), Information Systems Research, Article vol. 3, no. 1, pp. 60-95, Mar 1992.

[20] DeLone W. H. and McLean E. R., "The Delone and Mclean Model of Information Systems Success: A Tenyear Update," (in English), Journal of Management Information Systems, Article vol. 19, no. 4, pp. 9-30, Spr 2003.

[21] Duffy B. R., "Anthropomorphism and the social robot," Robotics and autonomous systems, vol. 42, no. 3-4, pp. 177-190, 2003.

[22] Epley N., Waytz A., and Cacioppo J. T., "On seeing human: A three-factor theory of anthropomorphism," (in English), Psychological Review, Review vol. 114, no. 4, pp. 864-886, Oct 2007.

[23] Esmaeilzadeh P., "How does IT identity affect individuals' use behaviors associated with personal health devices (PHDs)? An empirical study," Information \& Management, vol. 58, no. 1, p. 103313, 2021.

[24] Freeze R. D., Alshare K. A., Lane P. L., and Wen H. J., "IS success model in e-learning context based on students' perceptions," Journal of Information systems education, vol. 21, no. 2, pp. 173-184, 2010.

[25] Go E. and Sundar S. S., "Humanizing chatbots: The effects of visual, identity and conversational cues on humanness perceptions," Computers in Human Behavior, vol. 97, pp. 304-316, 2019.

[26] Gong T., Wang C.-Y., and Lee K., "Effects of characteristics of in-store retail technology on customer citizenship behavior," Journal of Retailing and Consumer Services, p. 102488, 2021.

[27] Groth M., "Customers as good soldiers: Examining citizenship behaviors in internet service deliveries," Journal of management, vol. 31, no. 1, pp. 7-27, 2005.

[28] Haan H. d., Nimwegen C. v., and Beun R. J., "Chatbot Personality and Customer Satisfaction," 2018.

[29] Helgesen Ø., "Are loyal customers profitable? Customer satisfaction, customer (action) loyalty and customer profitability at the individual level," Journal of Marketing Management, vol. 22, no. 3-4, pp. 245266, 2006.

[30] Henseler J., Ringle C. M., and Sarstedt M., "A new criterion for assessing discriminant validity in variancebased structural equation modeling," Journal of the academy of marketing science, vol. 43, no. 1, pp. 115$135,2015$.

[31] Hildebrand C. and Bergner A., "Conversational robo advisors as surrogates of trust: onboarding experience, firm perception, and consumer financial decision making," Journal of the Academy of Marketing Science, pp. 1-18, 2020.

[32] Ho C.-C. and MacDorman K. F., "Revisiting the uncanny valley theory: Developing and validating an alternative to the Godspeed indices," Computers in Human Behavior, vol. 26, no. 6, pp. 1508-1518, 2010.

[33] Holzwarth M., Janiszewski C., and Neumann M. M., "The influence of avatars on online consumer shopping behavior," Journal of marketing, vol. 70, no. 4, pp. 1936,2006

[34] Hsu J. S.-C., Lin T.-C., Fu T.-W., and Hung Y.-W., "The effect of unexpected features on app users' continuance intention," Electronic Commerce Research and Applications, vol. 14, no. 6, pp. 418-430, 2015.

[35] Huang Z. and Benyoucef M., "The effects of social commerce design on consumer purchase decisionmaking: An empirical study," Electronic Commerce Research and Applications, vol. 25, pp. 40-58, 2017.

[36] Hur J. D., Koo M., and Hofmann W., "When temptations come alive: How anthropomorphism undermines self-control," Journal of Consumer Research, vol. 42, no. 2, pp. 340-358, 2015.

[37] Innis D. E. and La Londe B. J., "Customer service: the key to customer satisfaction, customer loyalty, and market share," Journal of business Logistics, vol. 15, no. 1, p. 1, 1994.

[38] Kassim N. and Abdullah N. A., "The effect of perceived service quality dimensions on customer satisfaction, 
trust, and loyalty in e-commerce settings," Asia pacific journal of marketing and logistics, 2010.

[39] Kraus D., Reibenspiess V., and Eckhardt A., "How voice can change customer satisfaction: A comparative analysis between e-commerce and voice commerce," 2019.

[40] Lee D., Oh K.-J., and Choi H.-J., "The chatbot feels you-a counseling service using emotional response generation," in 2017 IEEE international conference on big data and smart computing (BigComp), 2017, pp. 437-440: IEEE.

[41] Lee Y.-C., Yamashita N., Huang Y., and Fu W., "' I Hear You, I Feel You": Encouraging Deep Selfdisclosure through a Chatbot," in Proceedings of the 2020 CHI conference on human factors in computing systems, 2020, pp. 1-12.

[42] Lewis B. R. and Mitchell V. W., "Defining and measuring the quality of customer service," Marketing intelligence \& planning, 1990.

[43] Mael F. and Ashforth B. E., "Alumni and their alma mater: A partial test of the reformulated model of organizational identification," Journal of organizational Behavior, vol. 13, no. 2, pp. 103-123, 1992.

[44] McAlexander J. H., Schouten J. W., and Koenig H. F., "Building brand community," Journal of marketing, vol. 66, no. 1, pp. 38-54, 2002.

[45] Moussawi S. and Koufaris M., "Perceived intelligence and perceived anthropomorphism of personal intelligent agents: Scale development and validation," in Proceedings of the 52nd Hawaii international conference on system sciences, 2019.

[46] Nelson R. R., Todd P. A., and Wixom B. H., "Antecedents of Information And System Quality: An Empirical Examination within the Context of Data Warehousing," Journal of Management Information Systems, vol. 21, no. 4, pp. 199-235, 2005.

[47] Nordheim C. B., Følstad A., and Bjørkli C. A., "An initial model of trust in chatbots for customer servicefindings from a questionnaire study," Interacting with Computers, vol. 31, no. 3, pp. 317-335, 2019.

[48] Nowak K. L. and Biocca F., "The effect of the agency and anthropomorphism on users' sense of telepresence, copresence, and social presence in virtual environments," Presence: Teleoperators \& Virtual Environments, vol. 12, no. 5, pp. 481-494, 2003.

[49] Ogbanufe O. and Gerhart N., "The mediating influence of smartwatch identity on deep use and innovative individual performance," Information Systems Journal, vol. 30, no. 6, pp. 977-1009, 2020.

[50] Parasuraman A., Zeithaml V. A., and Berry L., "SERVQUAL: A multiple-item scale for measuring consumer perceptions of service quality," 1988, vol. 64, no. 1, pp. 12-40, 1988.

[51] Petter S. and McLean E. R., "A meta-analytic assessment of the DeLone and McLean IS success model: An examination of IS success at the individual level," Information \& Management, vol. 46, no. 3, pp. 159-166, 2009.

[52] Puzakova M., Kwak H., and Rocereto J. F., "When humanizing brands goes wrong: The detrimental effect of brand anthropomorphization amid product wrongdoings," Journal of marketing, vol. 77, no. 3, pp. 81-100, 2013.

[53] Rahman A., Al Mamun A., and Islam A., "Programming challenges of chatbot: Current and future prospective," in 2017 IEEE Region 10 Humanitarian Technology Conference (R10-HTC), 2017, pp. 75-78: IEEE.

[54] Rose S., Clark M., Samouel P., and Hair N., "Online customer experience in e-retailing: an empirical model of antecedents and outcomes," Journal of retailing, vol. 88, no. 2, pp. 308-322, 2012.

[55] Sheehan B., Jin H. S., and Gottlieb U., "Customer service chatbots: Anthropomorphism and adoption," Journal of Business Research, vol. 115, pp. 14-24, 2020.

[56] Sundar S. S., The MAIN Model: A Heuristic Approach to Understanding Technology Effects on Credibility. MacArthur Foundation Digital Media and Learning Initiative, 2008.

[57] Touré-Tillery M. and McGill A. L., "Who or what to believe: Trust and the differential persuasiveness of human and anthropomorphized messengers," Journal of Marketing, vol. 79, no. 4, pp. 94-110, 2015.

[58] Wan E. W., Chen R. P., and Jin L., "Judging a Book by Its Cover? The Effect of Anthropomorphism on Product Attribute Processing and Consumer Preference," Journal of Consumer Research, 2016.

[59] Wang W.-T., Wang Y.-S., and Liu E.-R., "The stickiness intention of group-buying websites: The integration of the commitment-trust theory and ecommerce success model," Information \& Management, vol. 53, no. 5, pp. 625-642, 2016.

[60] Wang Y.-S., Lin S.-j., Li C.-R., Tseng T. H., Li H.-T., and Lee J.-Y., "Developing and validating a physical product e-tailing systems success model," Information Technology and Management, vol. 19, no. 4, pp. 245257, 2018.

[61] Wang Y. S., "Assessing e-commerce systems success: a respecification and validation of the DeLone and McLean model of IS success," Information systems journal, vol. 18, no. 5, pp. 529-557, 2008.

[62] Wells J. D., Valacich J. S., and Hess T. J., "What signal are you sending? How website quality influences perceptions of product quality and purchase intentions," MIS quarterly, pp. 373-396, 2011.

[63] Wen Y.-C., "Applied Modified Delphi Method to Researching Intelligent Customer Service Satisfaction.," National Sun Yat-sen University, Department of Information Management, 2020.

[64] Xu Y., Shieh C.-H., van Esch P., and Ling I.-L., "AI customer service: Task complexity, problem-solving ability, and usage intention," Australasian Marketing Journal (AMJ), 2020.

[65] Yuan L. and Dennis A. R., "Acting like humans? Anthropomorphism and consumer's willingness to pay in electronic commerce," Journal of Management Information Systems, vol. 36, no. 2, pp. 450-477, 2019. 